Document downloaded from:

http://hdl.handle.net/10251/65045

This paper must be cited as:

Trawick, P.; Ortega Reig, MV.; Palau-Salvador, G. (2014). Encounters with the moral economy of water: convergent evolution in Valencia. Wiley Interdisciplinary Reviews: Water. 1(1):87-110. doi:10.1002/wat2.1008.

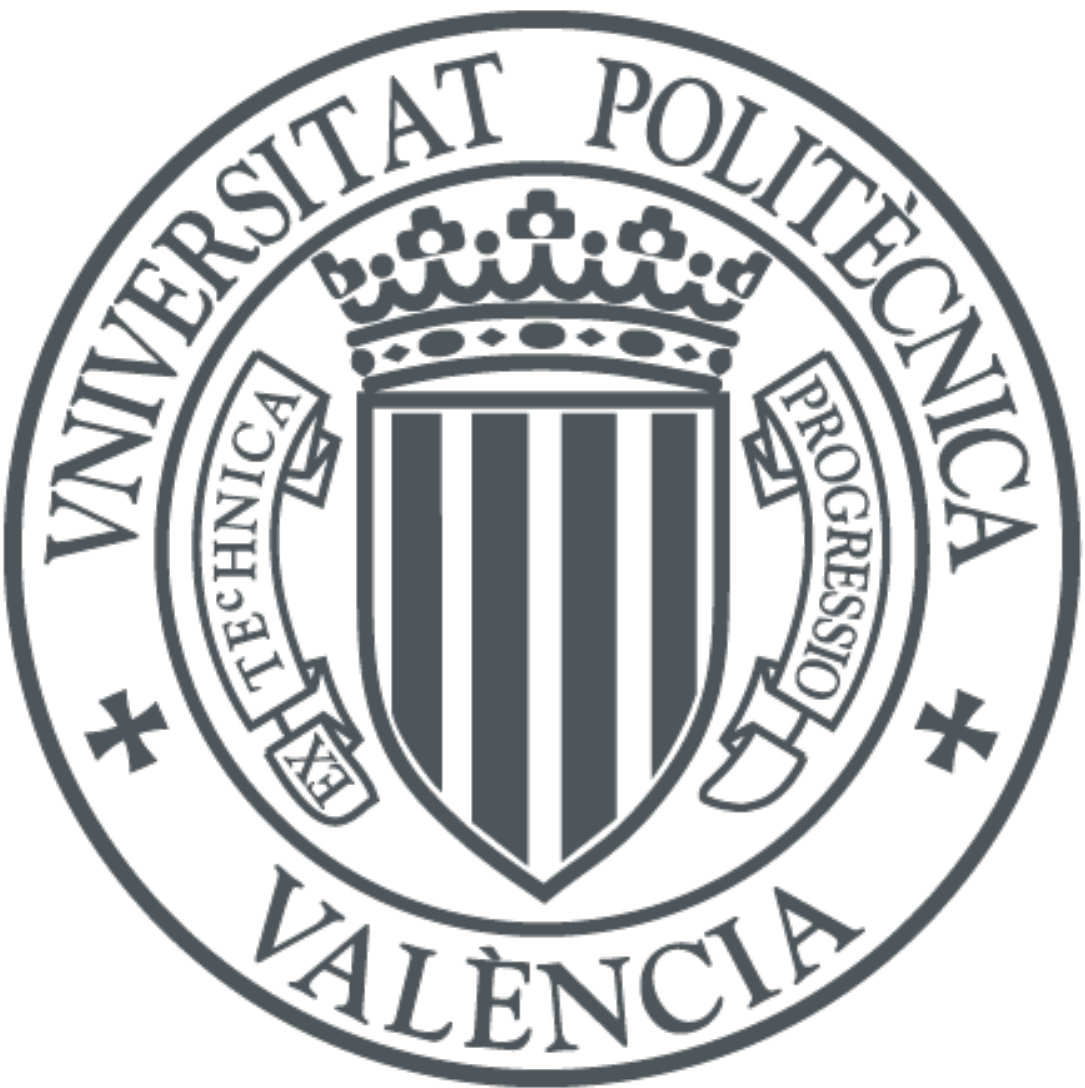

The final publication is available at

https://dx.doi.org/10.1002/wat2.1008

Copyright Wiley

Additional Information 


\title{
Encounters with the Moral Economy of Water: Convergent Evolution in Valencia
}

\author{
Trawick, Ortega-Reig and Palau-Salvador (2014), \\ WIREs Water, 1 (1), pp. 87-110. ${ }^{6}$
}

\subsection{Introduction}

As the population expands during the next century and the planet continues to warm, the amount of water available for human use will decline rapidly, further advancing in its present trend. The impact will be felt most strongly in irrigation - currently responsible for approximately $70 \%$ of total water use - where a growing shortage is either already present, as in many countries of the global South, or looming on the horizon to threaten long-term food security for the planet as a whole. An irrigation system is, theoretically, capable of adapting to this, consisting of some components that are self-organized, such as the water-user groups that farmers typically form, and others that are intentionally designed, such as the rules that specify how the resource will be utilized and shared by them under changing hydrological conditions. The special fascination of anthropologists and other social scientists with the technology is therefore not surprising; irrigation can, and often does, form the core of an especially dynamic kind of village-based agricultural society, one that provided the foundation upon which many early hydraulic civilizations were built.

Of particular interest, given today's impending water and food crisis, are robust systems (Anderies et al., 2004) having the capacity to maintain desired characteristics even in the face of environmental fluctuations such as the scarcities caused by seasonal low water and by periodic droughts, extreme events that are predicted to increase in frequency, duration, and scope during the coming decades (Burke et al., 2006). This use of an engineering term in reference to 'systems' having unique cultures and histories may

6. This is the accepted version of the following article: Trawick, Ortega-Reig and Palau-Salvador, Encounters with the moral economy of water: convergent evolution in Valencia, WIREs Water, 1 (1), pp. 87-110, 2014 which has been published in final form at doi: 10.1002/wat2.1008. 
be distasteful to some people, but the concept itself - one closely akin to resilience - has a theoretical and practical significance that can hardly be denied.

Another type of system has received a great deal of attention in recent years: those run according to rules and procedures established collectively by local farmers themselves, rather than by government bureaucracies. Throughout the world a large number of case studies have been done of community-managed systems, providing the primary data for subsequent comparative analyses aimed at determining what features these local hydraulic societies have in common (Agrawal, 2002; Baland and Platteau, 1996; Maass and Anderson, 1978; Ostrom, 2005, 1992, 1990; Tang, 1992). A trait shared by some of them, but by no means all, is a type of success compatible with robustness.

Some systems show a remarkable capacity to cope with both moderate and severe water scarcities while maintaining two social characteristics that are now accepted, at least by some authors (Ostrom, 1992, 1990; Tang, 1992; Trawick, 2010, 2008, 2001b), as indicators of desirable and apparently sustainable outcomes in irrigation: 1) all people who are entitled to receive water get their full share during each distribution round, including the "tail-enders" along each canal (an indicator of equity or fairness); and 2) the rate of water theft, the most disruptive form of cheating and free-riding, is extremely low or even virtually nil (an indicator of effective monitoring and transparency).

The most important questions about these locally governed systems have yet to be fully answered, however, ones that are crucial in explaining their success and their capacity to adapt. What institutions or rules enable farmers to cope collectively with climatic fluctuations; and which of these, if any, do most successful systems have in common? If farmers consider equity and transparency to be desirable characteristics, are those outcomes defined differently and achieved through very diverse rules in various environmental settings, as some authors argue (Boelens and Dávila, 1998; Boelens and Hoogendam, 2002; Boelens and Vos, 2012; Mosse, 2006a, 2006b, 2003)? Or is a single set of institutions capable of creating them, or helping to create them, in systems of widely different scales and levels of complexity, and of maintaining them during droughts? In other words, is there a single best or 'optimal' way of organizing communities to cope with fluctuation and scarcity, in different settings and across different scales?

The research to be discussed here was comparative and ethnological in that it attempted to answer these questions by determining if a particular set of principles, 
previously shown to govern several robust and successful systems in one part of the world - the Peruvian Andes (Trawick, 2005, 2003a, 2003b, 2001a, 2001b, 1994; Treacy, 1994a, 1994b) - also exists in a well-known system on the Mediterranean coast of Spain, a region notorious for having a number of impressive systems of this general type. Perhaps the most famous of all is the Huerta or garden of the city of Valencia, the main focus of this study. The goal was to determine if equity, transparency, and robustness are achieved in the same way there, in a multi-community system of medium scale, as in the aforementioned systems in Peru, which are small in scale and belong to tiny peasant villages in remote corners of the Andes.

A test of this hypothesis was interesting for several reasons, not least the fact that these local irrigation societies almost certainly evolved independently of each other, having emerged long ago as distinct Andean and Islamic hydraulic traditions (Trawick, 2010, 2008, 2003a, 2001a). If the rules and principles governing them today are indeed highly similar, as we will argue here - displaying striking parallels among systems that otherwise differ in many important respects - then the Valencian and Peruvian systems document one of the most striking examples of convergent social evolution ever identified in the ethnographic record. This convergence among societies evolving independently in different parts of the world is unprecedented and has important implications for social scientists as well as farmers, especially for small farmers who are struggling to cope with the growing scarcity and unpredictability of water being brought on by population growth and by climate change.

\subsection{Infrastructure and social organization in the Huerta, a multi-community system of medium scale}

The canal system of Valencia, on Spain's central Mediterranean coast, has been the focus of several classic studies in the irrigation literature (Glick, 1970; Maass and Anderson, 1978; Ostrom, 1990). Long regarded to be highly successful, and known to be extremely old, the system is governed democratically by approximately twenty thousand small farmers organized into ten relatively autonomous irrigator communities (or WUAs), whose apparently Islamic institutions are thought to date back to the time before the expulsion of the Moors in the medieval period. Here, the antiquity of the canal infrastructure and its communal mode of governance contrast sharply with the modern cosmopolitan setting: a city of approximately a million people, much of whose 
food is supplied by the Huerta or garden, a term used locally to refer to the canal system as a whole.

The famous Water Tribunal that governs the system has been meeting publicly every Thursday at mid-day in the city center - in the Apostles' Door of the main cathedral - for over seven hundred years ${ }^{7}$, to settle any disputes between farmers over water (Glick, 1970). This solemn oral court is impressive but often merely ceremonial, as the black-robed judges - elected leaders (Sindicos) of eight of the local WUAs - rarely have any formal complaints to consider. The frequency of conflict among farmers is amazingly low, as we will see, and this has clearly been the case for a very long time. Today the weekly ritual is invariably watched by hundreds of tourists, people drawn to Valencia by events like the its Formula One Grand Prix, the 2007 Americas Cup yacht race, or even the 2007 release of the Fourth Assessment Report of the UN's InterGovernmental Panel on Climate Change.

The canal network presently serves an area of 8,804 ha, land watered with the flow of the Turia River, whose volume today is closely regulated and smoothed out by three upstream dams. Nearly half of this land (3,792 ha) belongs to the members of the nine WUAs that participate in the Water Tribunal (see Figure 2.1 and Table 2.1), groups which are autonomous in the sense that each has its own written rules for using the river water, ordenanzas that can theoretically be changed at any time. These institutions have in fact been remarkably stable for centuries, and they turn out to be highly similar from one WUA to the next. A tenth and very large upstream WUA, called the Real Acequia de Moncada - which lies within the Huerta but does not participate in the Water Tribunal ${ }^{8}$ - shares the river flow through the uppermost main canal to irrigate 5,012 ha, or slightly more than half of the total area served.

7. The Tribunal meets weekly, since water use is supervised throughout the entire year. Although there are ten canal communities (or WUAs) in the Huerta, one of them, Moncada, does not participate, having its own Tribunal. Of the remaining nine, only eight are directly represented on the water court: the ninth, Xirivella, has its own Sindic but is represented in the Tribunal by the Sindic of Mislata, whose main canal it shares.

8. The area covered by the nine WUAs participating in the Water Tribunal is also referred to in other chapters as La Vega de Valencia or La Vega (the meadow of Valencia). This term is used to distinguish them from the neighbouring WUA of the Real Acequia de Moncada. 


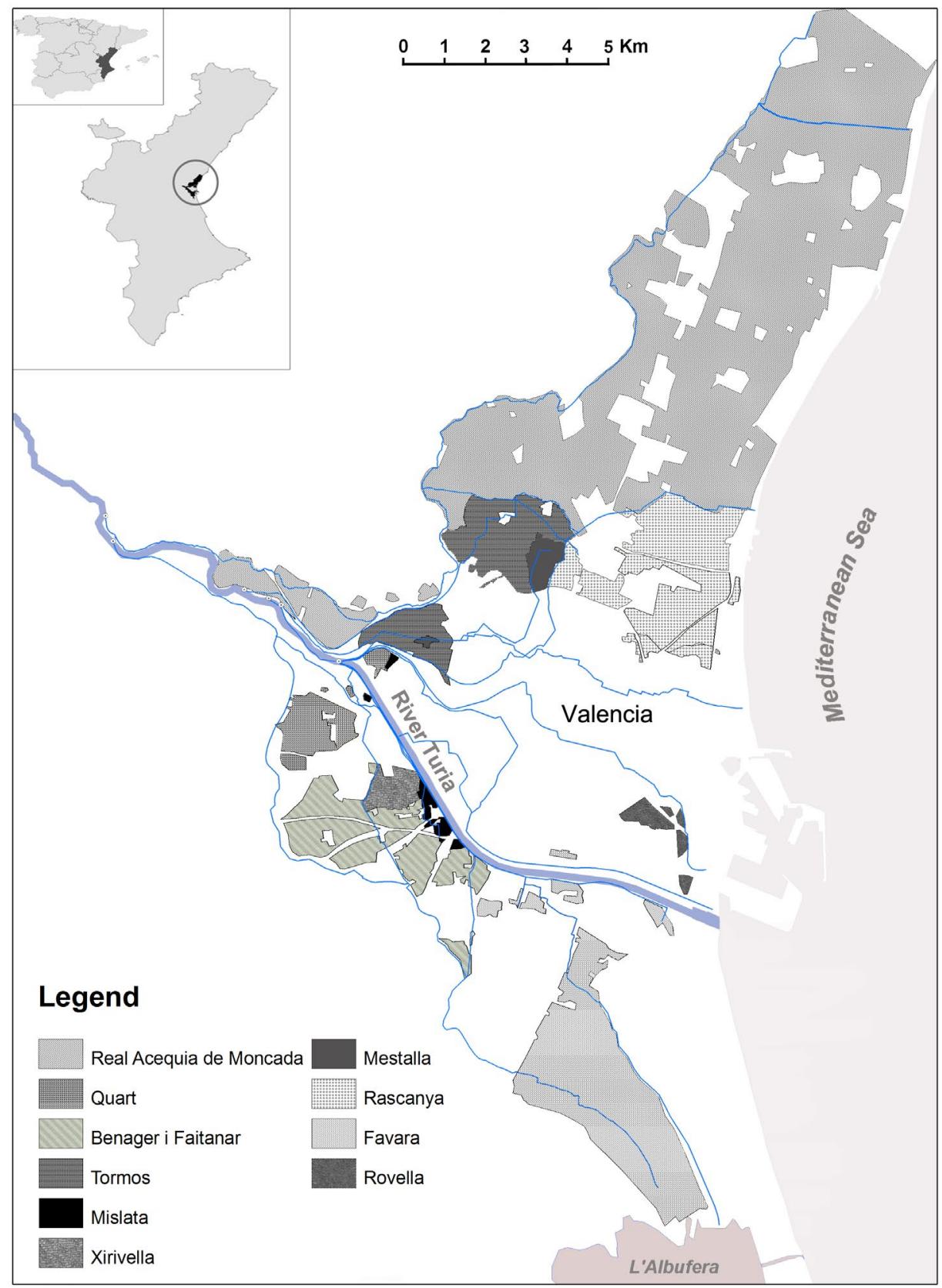

Figure 2.1. WUAs in the Huerta of Valencia.

The water shares drawn by each WUA from the river are fixed percentages of the total flow, diverted into the eight main canals by permanent weirs called azuds, an 
Arabic term dating back to the system's construction. The size of each flow was originally determined by the land area irrigated, service areas that until recently remained quite stable. In the last forty years, however, most of the WUAs have lost substantial amounts of land due to urban growth (see Table 2.1). Although their traditional allocations of river water have yet to be reduced accordingly, local farmers rightly feel threatened by this ongoing encroachment.

A less serious threat, and one that Valencians have longer experience in dealing with, is drought, the frequency of which is widely acknowledged to be increasing with climate change. Within most of the ten WUAs (but not all of them), local well societies ${ }^{9}$ were established gradually during the last century in order to assist in coping with it, cooperatives formed by farmers who pooled their money in order to drill into the underlying aquifer and thus share both the costs and benefits of additional water coming from the ground.

These groundwater irrigation groups - whose existence and importance were noted previously by Maass and Anderson (1978, p. 16) and Ostrom (1990, p. 71) today number in the hundreds, groups whose membership overlaps in each case with that of an encompassing WUA (Ortega-Reig, 2009). These essentially private irrigation societies are not a part of the Huerta's long tradition of communal water management, but they have been strongly shaped by its institutions, as we will see below, and they rest on the hydraulic and social foundation thus provided. The societies make it possible to integrate the use of the two sources of water, and they turn out to play a vital role in keeping commercial crop production viable during periods when the river water is scarce.

Because the WUAs have their own flows drawn from the river and their own rules for using that water, the Huerta appears at first glance to be a set of largely independent small-scale or "indigenous" systems, i.e., ones of less than 1,000 ha (Hunt, 1988; Mabry and Cleaveland, 1996). However, two of the user groups - Favara and Moncada - are substantially larger and technically of medium scale, while two others Quart and Benager-Faitanar — rely on a single weir and divide the flow of a main canal to irrigate nearly that amount of land. To classify Valencia as a set of separate small-scale systems is to overlook these complexities and also ignore the high level of cooperation

9. The term Groundwater User Associations (GUAs) or well associations is also used to refer to the same type of associations in other chapters of this thesis. 
routinely required — as we discovered in the research — to coordinate the timing of all the WUAs' water use so that they can irrigate together on a single cycle.

Table 2.1. Service areas of WUAs in the Huerta of Valencia in 2009 and 1965.

\begin{tabular}{|c|c|c|}
\hline & $\begin{array}{l}\text { Irrigated surface } \\
\text { in } 2009 \text { (ha)* }\end{array}$ & $\begin{array}{l}\text { Irrigated surface } \\
\text { in } 1965(\mathrm{ha}) * *\end{array}$ \\
\hline Canal of Quart (shared) & 939 & 1526 \\
\hline 1) WUA of Quart & 324 & ? \\
\hline 2) WUA of Benàger - Faitanar & 615 & $?$ \\
\hline Canal of Mislata (shared) & 165 & 769 \\
\hline 3) WUA of Mislata & 65 & ? \\
\hline 4) WUA of Xirivella & 100 & $?$ \\
\hline \multicolumn{3}{|l|}{ Have own main canal } \\
\hline 5) WUA of Tormos & 600 & 945 \\
\hline 6) WUA of Mestalla & 116 & 900 \\
\hline 7) WUA of Favara & 1057 & 1054 \\
\hline 8) WUA of Rascanya & 840 & 720 \\
\hline 9) WUA of Rovella & 75 & 415 \\
\hline Subtotal of communities in Water Tribunal & 3792 & 6329 \\
\hline WUA of Real Acequia de Moncada & 5012 & 3190 \\
\hline Total of all permanently irrigated lands & 8804 & 9519 \\
\hline Extremales (land with rights to surplus water only) & 563 & 6539 \\
\hline Favara & 359 & 2056 \\
\hline Rascanya & 0 & 580 \\
\hline Rovella & 204 & 93 \\
\hline Real Acequia de Moncada & 0 & 3810 \\
\hline Total Huerta lands & 9367 & 16058 \\
\hline
\end{tabular}

*Source: GIS data from Centro Valenciano de Estudios sobre el Riego. Published in the Plan de Ación Territorial de la Huerta Valencia (PATH), table 2.2-3, p. 54, http:/ / cam.gva.es/condenido/62478/cas/I MI 2-2.pdf

**Source: Maass and Anderson (1978)

The Huerta stretches across an extensive delta and floodplain that underlies the growing city, fanning out near the point where the Turia River empties into the Mediterranean Sea. The rich alluvial soils and the temperate and largely frost-free climate enable farmers to produce two or three crops per year, much of it for sale in local, national, and even global markets. The chief products, which typically are also consumed daily by the landowning households, are potatoes, onions, melons, a wide array of garden vegetables, and even a local variety of paella rice, together with the oranges for which the surrounding region is famous. Local agriculture is thus heavily 
commercialized, even though the farms are quite small in nearly every case. In their classic study published more than thirty years ago, Maass and Anderson (1978, pp. 11,40 ) noted that fewer than $1 \%$ of the farms were bigger than 5 ha, while $83 \%$ were smaller than 1 ha, a highly fractured minifundia pattern that still prevails today, as shown in Table 2.2.

Table 2.2. Pattern of landholdings in the WUA of Real Acequia de Moncada in 2009.

\begin{tabular}{cccccc}
\hline Size Range & $<1$ ha & $1-3$ ha & $3-5$ ha & $>5$ ha & Total properties \\
\hline Number of properties & 9196 & 537 & 26 & 14 & 9773 \\
$\%$ of all landowners & $94.10 \%$ & $5.50 \%$ & $0.03 \%$ & $0.01 \%$ & $100 \%$ \\
\hline
\end{tabular}

Valencia is therefore a multi-community system of medium scale, but it remains a smallholder system, like the previously-studied examples in Peru, one composed of household production units that, in terms of their size and labor organization, closely resemble those that generally prevail today in developing countries. The similarity ends there, however; for if Valencia's farms are overwhelmingly of this 'peasant' type, they are certainly among the most productive such farms to be found anywhere in the world. The droughts are a major handicap, but the Huerta's farms remain extraordinarily productive in spite of them, mainly because people cooperate so effectively in adapting and in sharing the impact of scarcity.

\subsection{Methods used in the fieldwork}

The research was conducted in four distinct periods: an initial one during a five-month stint in the spring and summer of 2004 (Trawick, 2010, 2008), a second in June and July of 2009, shortly after the end of a severe three-year drought (Ortega-Reig, 2009), a third extending throughout 2010 (Ortega-Reig, 2011), and final one in the spring and summer of 2013. The early fieldwork focused on testing the hypothesis of convergent evolution; however, the drought's onset in 2005 provided an opportunity to study the system's robustness in adapting to fluctuation and severe scarcity, thus encouraging a continuation. Yet there were other reasons why a close re-examination of the rules and principles governing irrigation in the Huerta was necessary.

First of all, the work of Maass and Anderson (1978, p. 26), although without peer in the irrigation literature, had provided crucial data that needed further verification 
and updating. Maass's account had argued that the system was both equitable and efficient, with water rights based on a principle of "proportionate equality"; but it did not document the frequency of irrigation for the various user WUAs, or for the thousands of individual farmers, at different times of the year. His definition of that term - one later shortened and clarified by Ostrom (Ostrom, 2005, 1992, 1990) to the more familiar "proportionality of costs and benefits" - did strongly imply that the watering frequency was the same for everyone, as it is in the previously studied systems in Peru. But such uniformity was not defined as a basic principle in either of those accounts, in a system where water distribution was shown to be, from the viewpoint of an outside observer, extremely complicated, with irrigation occurring simultaneously within a single canal community (or WUA) in as many as thirty different places.

There was thus a need to confirm that this principle - the most important one driving the dynamics of the aforementioned model - was operating, and to show that it was recognized to be significant by the local farmers. This would amount to verifying, through interviews, that the system is indeed effective in providing every entitled person with their rightful share during each distribution round - a task that, it should be noted, remains unfinished for most of the 'successful' systems reported to date in the world literature on irrigation.

A similar criticism applied to the monitoring of water use at the level of the field and the 'individual' irrigator. The importance of mutual monitoring by the farmers themselves was overlooked by Maass and Anderson, who implied that vigilance within the system was handled adequately by the distributors and guards of the water, the Guardas, full-time professionals who are employed by each irrigator group. Ostrom (1990, pp. 73-75), in later calling overdue attention to it, had sustained some of the earlier observations of Glick (1970) in his classic historical study. Both Glick and Ostrom had noted that the level of monitoring by the farmers of each other was very high, also observing that this was in part made possible by the fixed order of people's turns along each canal. But neither author had apparently had the opportunity to ask any farmers about this. If a model derived from much smaller systems in another part of world was to be tested in Valencia - a model based on clearly-defined principles of equity and transparency- then the effort obviously required a closer look.

Maass's description, which provided most of the data used later by Ostrom, had relied heavily on earlier sources published in Spanish, many of them official records and 
publications of the ten WUAs. He had apparently also interviewed some people, but provided no information about this, giving the impression that the primary data came either from those earlier published sources or from the elected leaders of the user groups. Recent critiques prominent in the literature have shown that the rules supposedly governing communal irrigation systems often turn out to be idealized representations that bear little resemblance to social reality (Mosse, 2006a, 2006b, 2003). Those flattering images can still be very useful to local water officials, especially in dealing with inquisitive outsiders. A re-study was therefore necessary, one that relied more on interviews, was explicit about sampling, and made an effort to include ordinary farmers.

Finally, there was the fact that Moncada, the largest canal WUA by far, had been neglected somewhat in the previous studies. There appeared to be several possible reasons for this, but Maass and Anderson's account (1978, p. 411) gave the impression that Moncada - which has its own set of twelve elected Sindics and even its own Water Tribunal - has distinct rules for using its portion of the river flow, especially during droughts. Luckily, an opportunity presented itself early in 2010 to extend the study to include this part of the canal system and to fill a significant gap.

Our methodology departed in interesting ways from the approach normally adopted in doing semi-structured interviews. From the start we were aware that water rights in the Huerta are complex, involving the use of both surface and groundwater under changing conditions, but that, in the case of the surface water - the foundation of the traditional system - they appeared to conform to the aforementioned model. Since our main goal was comparative and ethnological - determining whether or not that Andean model did fit local practices - a set of yes/no and multiple-choice questions was drawn up, based on the principles comprising the model, and used as a guide for the interviews. For example, one question explored whether or not the irrigation frequency is the same for all ten WUAs, and for all of the farmers in each one, whenever scarcity prevails. This was done by giving people the opportunity to agree or disagree with a statement to that effect, on a 5-point Likert scale.

Although such structured questions could perhaps be considered leading ones, which are not appropriate for ethnographic research, we used them in a novel way designed to 'open them up' and counteract this effect, making them suitable for ethnology. The goals of the discussions in each case - lengthy conversations guided through prompting by the interviewer - were to have the farmers and other participants 
choose a response to the question as stated, while also commenting on whether or not this was an easy thing to do. We found that, when used interactively in this way, even a yes/no question would usually elicit a lengthy response - typically "yes, but...", or "no, but... - and ultimately yield a lot of useful information.

Note that the questions or statements did not specify which of the water sources was being referred to: the river water or the groundwater. Instead, people were encouraged to provide that information in the process of choosing and explaining their answers. The initial choices that people made on the Likert scale were not altered in numerically compiling the results, even if the subsequent explanation indicated that it rightly should be, as happened numerous times. By using otherwise closed questions in this open-ended but structured way, we were able to deconstruct the set of rights and duties underlying irrigation today in the Huerta.

A total of 113 interviews were conducted, with local water officials - people who were either currently serving, or had formerly served, in the water-user groups - and with ordinary farmers. A purposive snowball method was used to identify the former subset, a pool of 48 Sindics (elected user-group leaders, who are themselves farmers) and Guardas (professional Water Guards, who generally are not), some of who were interviewed twice in separate samples done several years apart ${ }^{10}$. The 59 farmers were interviewed once and selected through a modified convenience sample, with most of them contacted initially in the fields while irrigating. The sample also included 6 regadores, contracted irrigators who, although not landowners themselves, derive their livelihood by performing this service on a long-term basis for local farmers.

Table 2.3. Categories and numbers of informants.

\begin{tabular}{cccc}
\hline Informants & Tribunal Communities & Moncada & Total \\
\hline Sindics & 9 & 2 & 11 \\
Guardas & 29 & 8 & 37 \\
Farmers & 33 & 26 & 59 \\
Regadores & 0 & 6 & 6 \\
TOTAL & 71 & 42 & 113 \\
\hline
\end{tabular}

Members of all ten WUAs were included in the sample, including, during the 10. The Sindics and former Sindics are farmers and landowners, as required by customary law, but are not paid a salary. The Guardas or Water Guards are full-time salaried professionals, a highly skilled position often handed down in local families, with fathers training their sons. 
final period of the research, 42 informants of both types in Moncada. The total number of farmers ultimately interviewed, including the Sindics and the appropriate Guardas, turned out to be 75 . The conversations were taped, and notes were taken in order to prepare transcripts of the interviews, which lasted from half an hour to one-and-a-half hours in every case. Trips to the canals and fields were also made, accompanying the Guardas, to observe the complexities of water distribution and to discuss the methods for irrigating the different crops.

Although we could not even begin to attempt a statistically significant sample of the nearly twenty thousand local farmers, the answers given by people were ultimately in such close agreement, and they triangulated so well with the information contained in the historical documents, the ordenanzas, and the earlier published accounts, as to provide a convincing portrait of how things are done today in the Huerta. It largely corroborated the data presented earlier by Glick, Maass and Anderson, Ostrom, and others, while providing important clarifications, updates and corrections, ones which confirmed that the hypothesized model does fit local practices.

\subsection{Results: the distribution and use of seasonal low water}

The interviews revealed that, in the management of the river water - the foundation of the local tradition - equity and transparency are achieved in the same way, by means of a nearly identical set of principles, in Valencia as in the aforementioned systems in Peru. Importantly, this generalization also applies to Moncada, so that all ten of the Huerta WUAs can be said to have converged on the same basic 'model' despite the autonomy enjoyed during much of their evolution.

The governing institutions, listed below in Table 2.4, are defined here as operating principles in order to indicate that in most cases they are derived through one small step of conceptual abstraction - a step easily recognizable to the local farmers - from one or more of the specific working rules, as explained to us in the interviews or as recorded in the ordenanzas. Despite their many differences, those rules are similar enough in the Peruvian and Valencian traditions that the institutions operating in one system and country would be easily understood by the farmers residing in the other.

Note that the principles overlap with, and are entirely consistent with, the design principles identified by Elinor Ostrom in her ground-breaking work (Ostrom, 2005, 1992, 1990) on the successful management of this particular "common-pool" 
resource, comparative work that greatly influenced and inspired our own. Our goal was merely to come up with a set of institutions that is more complete and somewhat more precise than hers, also being a bit closer conceptually to the actual working rules in each of the local systems that have been compared.

The principles in most cases specify a form of moral self-restraint that farmers routinely impose on themselves in using water under conditions of scarcity, an upper limit on consumption that helps to avoid waste of the resource, to maximize its availability, and, above all, to minimize social conflict. The principles thus reveal the moral core lying at the heart of the working rules, which appears to be basically the same in all of the local systems that have been studied. By employing this kind of analytical logic, it becomes possible to appreciate the unique way that the principles interact with each other, forming a kind of integrated whole or model that both shapes and reinforces people's inherent willingness to cooperate, as we will see below.

The principle of autonomy has already been discussed but requires some clarification. The power of the ten WUAs to set and modify their own rules was recognized by almost everyone interviewed, as shown in Figure 2.2, but also acknowledged to be limited. People are very much aware that the local user groups have long played a central role in managing their own resources, enjoying the kind of freedom that all such groups in Spain now have under the water law of 1985 and the Real Decreto Legislativo of 2001 (BOE, 2001; Gimenez-Casalduero and Palerm-Viqueira, 2007). In their previous study, Maass and Anderson (1978, p. 48) observed that this local power had not diminished, even after the State built three storage and regulation dams on the Turia River, beginning in the 1950 's, to smooth out the yearly fluctuations in the supply. But this is no longer entirely true.

The canal WUAs now function in coordination with the Júcar District Water Authority (JDWA), the bureaucracy that operates the dams. Given the beneficial service provided, they are receptive to its suggestions for improving existing arrangements for water use, within the general constraints expressed in the traditional operating principles. Hence, as Ostrom has rightly noted (2005), the WUAs operate today within a nested hierarchy of other institutions, including those introduced by the JDWA and the Spanish government. The autonomy they enjoy is a limited one, simultaneously modern - informed by hydrological science and the use of up-to-date technology and yet based largely on moral principles dating back to Islamic times. 
Table 2.4. Operating principles of irrigation under scarcity in Valencia.

Autonomy - each community has and controls its own flow of surface water, which is distributed and used according to customary rules;

Alternation or turn-taking - the sets of communities on either side of the river cooperate by alternating in extracting their assigned flows, in such a way that they irrigate together in a single cycle; their individual farmers do likewise, taking turns in order to share the resource in the same coordinated way;

Contiguity in distribution - within the communities in each half of the system (i.e. on the two sides of the river), water is distributed to fields in a relatively fixed contiguous order based only on their location, starting at the upper end and moving systematically downward, canal-by-canal and field-by-field*, until all of the eligible lands have been irrigated.

Uniformity (one component of equity or fairness):

- among rights: all entitled fields receive water with the same frequency, so that the impact of the prevailing scarcity is shared and absorbed evenly by all of them;

- in techniques: all farmers irrigate their crops in the same way, using one of two standard methods that in each case impose an upper limit on water consumption and on irrigation time, thereby creating a fairly uniform land-towater ratio throughout the canal system;

Proportionality (the other component of equity):

- among rights: in taking their allocated turns, irrigators use only the amount of water to which the extent of their land, and the specific watering technique being utilized, entitle them;

- among duties: people's contributions to canal maintenance must be proportional to the amount of irrigated land that they have, and thus to the amount of water that they use; (also between rights and duties) .

Transparency - everyone knows the distribution rules and, because the proper order of turns is fixed and contiguous along each canal, they have the ability to confirm, with their own eyes, whether or not those rules are being obeyed, to detect and denounce any violations that occur.

Boundary maintenance - any unauthorized expansion of irrigation, which would lower the frequency of water use for everyone, is prohibited.

Direct feedback on the level of free riding - the frequency of water use for everyone is determined, in a direct and obvious way to each farmer, by the extent to which people are obeying the rules.

Graduated sanctions - the penalties for rule violations are severe but vary according to the gravity of the offence.

*The use of favour water, or agua de gracia, presents a partial exception to contiguity (Maass and Anderson, 1978, p. 27), wherein the Guards shift water between canals in order to speed up irrigation in areas where it is lagging behind. But the same top-tobottom rule reportedly governs this somewhat opaque process. 
The second principle, alternation, was not recognized by Maass and Anderson as part of the normal way of operating during the dry season, but today it is. The research revealed that this arrangement, which is not entirely new, was instituted by the WUAs, by mutual accord but at the suggestion of the JDWA, in the late 1970's or early 1980 's, when it was recognized as the best arrangement for operating during seasonal low water. It is a minor alteration of the traditional procedure for adapting to drought, referred to by Maass and Anderson (1978, p. 29) as "la dobla". Importantly, the change followed an earlier move by some of the canal WUAs to extend full water rights to all of their formerly irrigated lands, including many extremales, lands that had previously been entitled only to excess or surplus water when that was available (Ortega-Reig, 2011; Sales Martínez, 1988). This seems to have been a consequence of the improvements in and stabilization of river flow that resulted from the construction of the three reservoirs, particularly that of Benageber, starting in the 1950's.

Although several WUAs agreed to the latter change, Moncada was the one that benefitted most, as revealed by the figures in Table 2.1. Far fewer extremales existed in most of the other WUAs, and the inclusion of some of them failed in those cases to counteract a contraction of irrigated land due to urban encroachment, a process that is still ongoing today. Interestingly, the major expansion in Moncada did not entail any increase in the WUA's assigned portion of the river flow, so that it did not compromise the existing rights of the other WUAs and farmers in the Huerta. Because of it, all of its farmers now have full rights to the surface water, and all of them irrigate in one coordinated cycle.

Each week, Moncada and the other WUAs lying downstream irrigate simultaneously, by dividing the river flow roughly in half. However, the nine WUAs of the inner Huerta (i.e. the members of Valencia's Water Tribunal) alternate in using their portion, with the groups on the right bank (Quart, Benàger-Faitanar, Mislata, Xirivella, Favara and Rovella) irrigating from Monday through mid-day on Thursday, and those on the left bank (Tormos, Mestalla, and Rascanya) irrigating from mid-day on Thursday through Sunday (Guinot, 2007). By taking turns in this way, all of the WUAs, including Moncada, are able to stay on the same schedule, equitably sharing the prevailing scarcity.

The principle of contiguity was recognized, at least implicitly, by all of the previous researchers, and was again vetted by almost everyone interviewed in our study (see Figure 2.2). The general rule for water distribution under scarcity in Valencia is 
"from up above to down below", but the interviews and first-hand observation revealed that there are two variations in how this contiguity principle is expressed in practice. Although a strict top-to-bottom order is followed in several cases, as in Moncada and Benàger-Faitanar, some WUAs - Quart, Tormos, Xirivella, Rascanya, and Rovella - use an inscription system to record the exact order in which their farmers will irrigate, in situations where people sometimes forfeit their turns.

Here the traditional top-down order of rights serves as the model, but before each cycle begins the farmers must write their names, on a blackboard located at the head of the canal, in order to express their intention to exercise their right and to avoid being skipped in the order. In other WUAs no signature is needed, but there the traditional rule is that each farmer must arrive at his field before the next farmer below him begins to irrigate in order to take his normal turn. If he is late in arriving he must wait, thus experiencing a small delay, but if he arrives even later, after his immediate downstream neighbor has finished, he loses his turn and must wait until the next round.

The meticulous nature of these rules helps to illustrate one of the main advantages of a contiguous watering order, which had been identified in the previous research in Peru (Trawick, 2003a, 2001a, 2001b). Several farmers noted this advantage and felt that it explains why the contiguity rule exists in all ten of the Huerta WUAs (Ostrom, 1992). As both Glick (1970) and Ostrom (1990) observed in their accounts, because field preparation and other routine chores are concentrated in one small expanse of land at a time - rather than being more spread out, as in other kinds of systems (Trawick, 2001b, pp. 21-22) - irrigation is a highly-visible, public activity. Neighboring farmers are routinely able to observe each other irrigate, and also to watch the work of the water distributor. The contiguity principle thus helps to create a highly transparent system, of which more will be said below. It also minimizes - as all local farmers seem to understand - the total surface area of canals in use at any point in time, correspondingly reducing evaporation and filtration and thereby maximizing the frequency of irrigation for everyone.

Uniformity in the watering frequency, the most important principle of all, was confirmed by the vast majority of people - with $96 \%$ either agreeing or strongly agreeing that it is the same for everyone within each WUA, and $86 \%$ affirming that it is uniform between all ten WUAs, as shown in Figure 2.3. But it was not affirmed by everyone, and here the disagreements revealed important details of how the system works. Numerous 


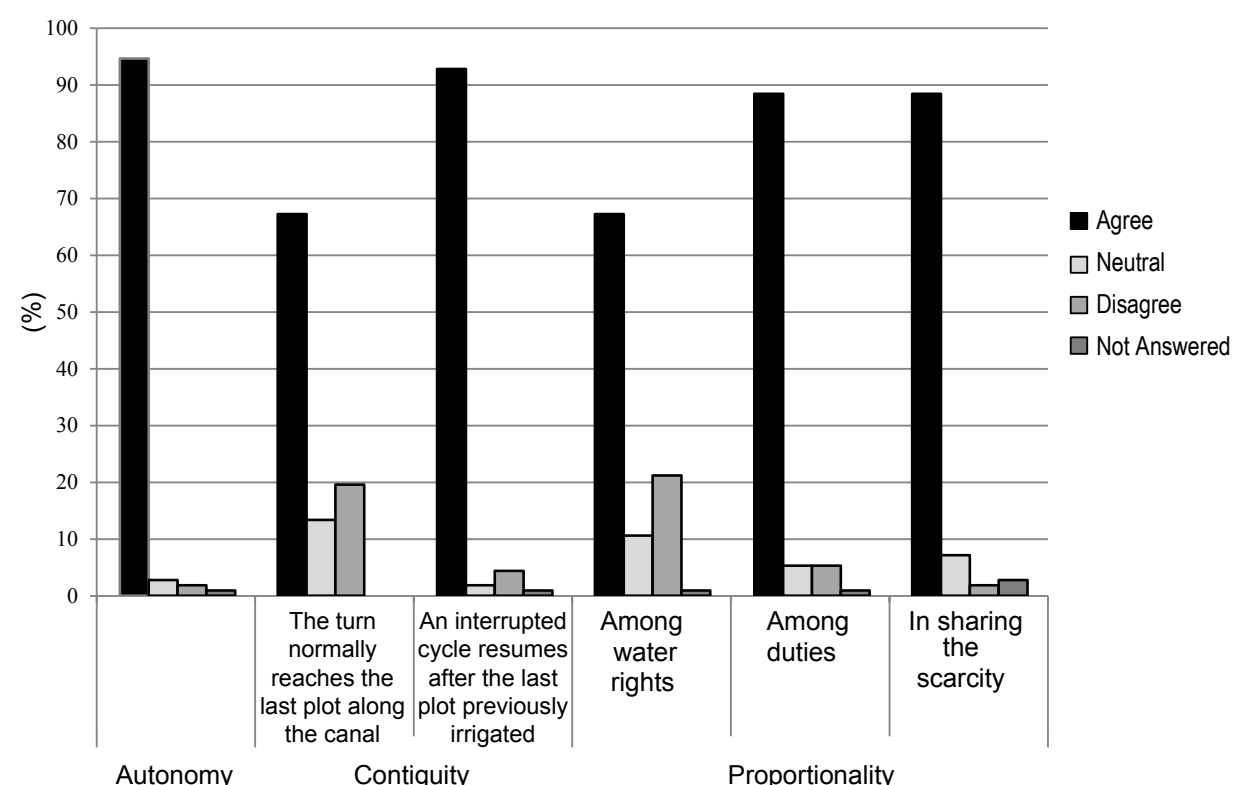

Figure 2.2. Percentages of responses to questions about the operating principles.

people (5\% of the total) pointed to the "tail-ender" WUAs - e.g. Mislata, also certain parts of Rascanya - lying along the far end of a main canal in the lower part of their half of the system. The farmers here actually irrigate continuously, using surplus water draining from the upstream WUAs in order to water their fields at a slow pace, up until the time when the WUAs' formal turns come around in the general cycle. At that point the process speeds up dramatically, with farmers using the entire canal flow to continue until all of the remaining lands have been serviced, at which point the cycle returns again to the upper part of the system.

During the low-water conditions of a typical dry season, the result in any case is a watering frequency that in fact conforms to the rhythm prevailing in the rest of the system. Today this can vary from once per week to a maximum of once every two weeks, depending on the degree of the prevailing scarcity. A few additional people — farmers in every case - expressed uncertainty about this issue, noting that they did not own fields in different parts of the system and thus could not say for sure that the frequency was the same everywhere. Yet everyone agreed that it was supposed to be the same according to some apparently unwritten rule of equity ${ }^{11}$.

11. Nowhere in the WUA's ordenanzas is there a rule stating that the watering frequency must be 
The other $5 \%$ of people who disagreed pointed to the use of the groundwater as creating exceptions. However, further investigation showed that the use of the wells, within the localized areas where the groundwater is extracted and made accessible, does not actually violate the principle of uniformity among rights, as we will see below. The issue is complex, but the groundwater is not generally used as a communal resource in most cases people have to purchase it - and its utilization is not directly governed by, although interestingly enough it is strongly shaped by, the Huerta's traditional communal institutions.

A certain uniformity of watering technique was ultimately acknowledged by everyone interviewed, and this proved to be perhaps the easiest principle to confirm, despite the fact that watering methods in the Huerta actually take two distinct forms. Here it is important to note that, just as in Peru, this relative uniformity is only possible because all fields in the Huerta have been terraced. The local farmers carefully levelled the entire landscape, and have since maintained it annually at substantial labor cost, in order to create this effect and to maximize the absorption of the water. Two different methods are used to accomplish this maximization; however, all farmers agreed that both are employed in a highly standardized way for each crop, a uniformity that had been identified as crucial in the systems studied previously in Peru.

The first method, of building ridges and furrows in the fields to pool the water - features called caballones - is the most widely used and is almost universally employed in growing garden vegetables. Here the width of the raised ridges varies somewhat, being determined by the size of the mature plants, but the furrows or canals between the ridges are excavated to a standard minimum width - one specified in the WUA rules as "dos daus", or about $40 \mathrm{~cm}$.- and to a depth sufficient to hold 10 to $15 \mathrm{~cm}$. of water.

Similar observations apply to the other technique, riego a manta, which involves drawing water in a thin "blanket" (5 to $10 \mathrm{~cm}$. deep) over shallow rectangular pooling structures called tablas, whose surface area is limited by custom. They are formed by low earthen walls located between the scratch canals, and enclose the areas actually cultivated. Although this method can be used to water almost any crop, the technique is mainly used to irrigate oranges and other citrus fruits. Most informants recognized that the two methods, being highly uniform, impose an upper limit in each case on water

the same for all farmers. Moreover, the Huerta as a whole has no written rules. Such uniformity, both within and between the WUAs, is a principle that could only be inferred from the earlier published accounts and then explored in the interviews. 


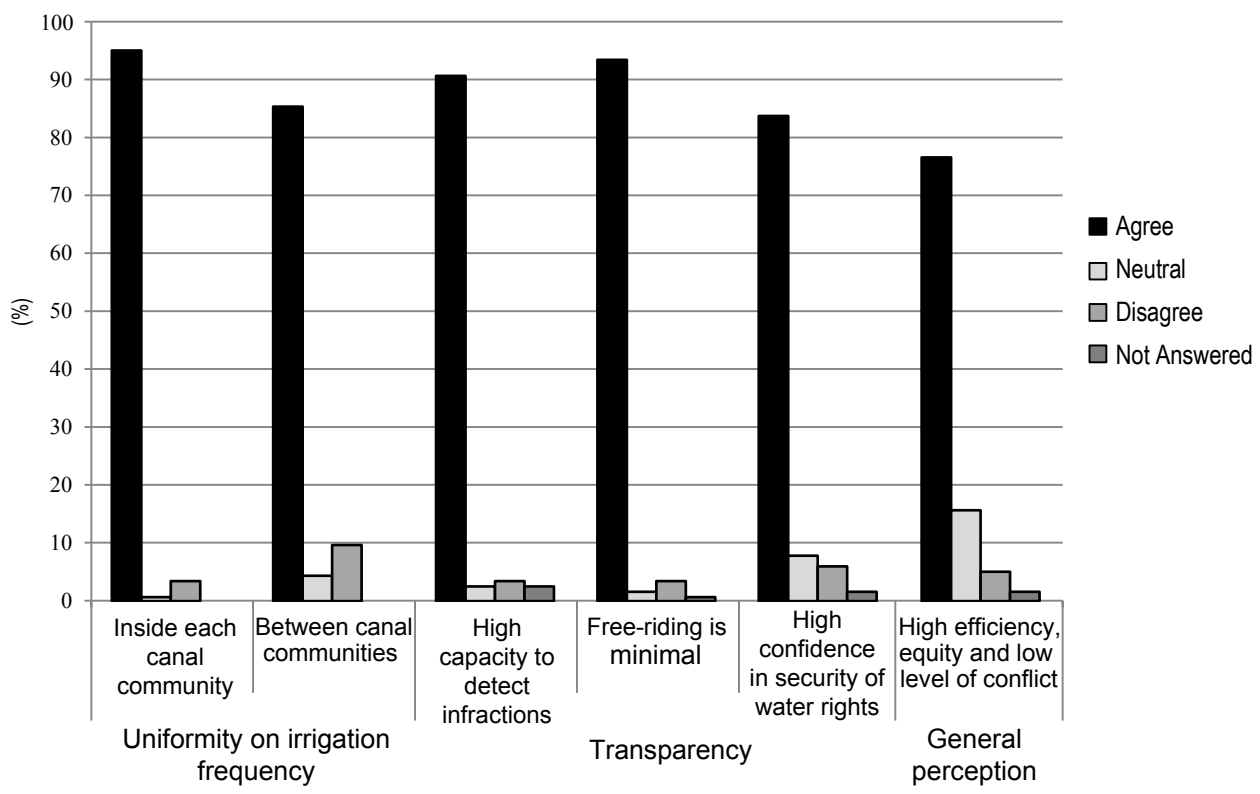

Figure 2.3. Percentages of responses to questions about the operating principles.

consumption and on irrigation time, thus creating the rough proportionality that is seen as basic to water rights in the Huerta.

The principle of proportionality, long cited as the basis of local water allocation (Maass and Anderson, 1978; Ostrom, 2005, 1992, 1990), was immediately recognized by nearly everyone interviewed (see Figure 2.2), but contested somewhat in terms of how well it actually fits local practices. Although most farmers (68\%) agreed that water rights are proportional to the land area irrigated in each case, and therefore to each other, some remained neutral on the issue, expressing ambiguity (11\%), while a significant number disagreed $(21 \%)$. Nearly all of the latter pointed out that, when taking their individual turns, people use as much water as they need to, with the precise amount depending on a number of factors - the specific crop and the watering technique, even the condition of the particular field — and these are ultimately decided by the farmer.

Despite these differences in perception, the use of the river water evidently continues to be seen by the vast majority as equitable and fair, based on its uniform frequency as well as its proportionality to the land area irrigated. People's corresponding duties to contribute to maintenance of the canal system - which in Valencia mainly take the form of a monetary fee paid annually for water use - are also seen as fair because they 
are directly proportional to those rights (affirmed by $88 \%$ of the interviewees). And the fees must be paid if people are to continue to get their water. Thus, as all of the earlier studies indicated - but did not have the opportunity to demonstrate - a pervasive fairness and proportionality are apparently perceived by most people to exist among rights, among duties, and between rights and duties (see Figures 2.2 and 2.3).

Here the only novelty to emerge in the interviews was to confirm emphatically that - as in the Peruvian systems - the most important factor defining equity or fairness in the eyes of local farmers is the uniform frequency, with the amount of water consumed by farmers in each turn being considered far less important. In order for rights to be proportional to each other, and thus to be equitable or fair under conditions of scarcity, the frequency must be the same for everyone. This may seem an obvious point but, as we will see later, it has important implications for how one should view the many other systems in the world where such proportionality - but not uniformity - is reported to exist.

A high degree of transparency was acknowledged by nearly everyone to exist within the system, as shown in Figure 2.3, and most farmers understood that this feature is largely created by the contiguous pattern of water distribution. The principle is vital because it provides farmers with a basic sense of security (affirmed by $84 \%$ of the interviewees) by making it possible for them to assist in enforcing the rules and thereby to protect their own water rights. Significantly, in discussing its importance people generally agreed that transparency is the main reason why the frequency of water theft has always been remarkably low in Valencia. 54\% of the people interviewed estimated that the frequency was either extremely low or virtually nil, while a total of $94 \%$ thought that it was low or better than that. This important issue will be discussed further below.

Two of the remaining principles, boundary maintenance and graduated sanctions, which were first identified by Ostrom $(2005,1992,1990)$ - and which are not shown in Figures 2.2 and 2.3 - were again confirmed by almost everyone in the study, with many people noting that they are crucial in explaining why the local tradition works so well. Note, however, that the system has been expanded - by mutual agreement among the farmers and their representatives - in the recent past, by incorporating the aforementioned extremales in some WUAs. Despite this, people generally gave very high ratings to Valencia's system, as shown in Figure 2.3, in terms of its general effectiveness, as compared to other irrigation systems in Spain with which they were familiar: $43 \%$ 
rated it as optimal, or the best that people can do, while another 34\% rated it as superior to all others in the country. Only 15\% rated it as average, and just $8 \%$ of people felt that it rated worse than that. This reflects great pride in the system, for which the local farmers are well known, but also expresses a high level of confidence in the effectiveness of its institutions, revealing one of the main reasons why people tend so strongly to obey the rules. The final principle, direct feedback on the level of rule conformance, will be discussed below.

The more pessimistic people interviewed, although few in number, placed great emphasis on certain inequities that have emerged recently in the in the use of nontraditional sources of water, to be examined below. This dissatisfaction is significant because it again confirms, by implication, the fundamental moral importance of a uniform frequency of irrigation, while also revealing an emerging and growing threat to the system, one that could ultimately cause cooperation among the farmers to break down.

\subsection{Results: the distribution and use of water during droughts}

The drought that began in 2005 was the worst of the last fifty years, posing a stiff test of the farmers' capacity to adapt through collective action. The failing rains soon caused the water stored in the upstream reservoirs to decline to half its normal level, leading the JDWA to declare a state of drought pre-alert early in 2006 (BOE, 2007; MAGRAMA, 2007). The WUAs of the Huerta, like others throughout the watershed, were required to find ways of reducing consumption accordingly, by $50 \%$, so as to adjust to the slower rate at which water would henceforth be released from the dams.

The Sindics conferred and accomplished this contraction very quickly, by implementing a traditional procedure - again, known as "la dobla"- which was modified slightly to fit the new circumstances. This extended the general watering cycle from its previous duration of one week to a total of two weeks, a frequency that prevailed thereafter throughout most of the Huerta until the drought ended three years later.

The elongation was accomplished mainly by altering the sharing arrangement between WUAs: Moncada and the groups of the inner Huerta simply began to alternate and to use the entire river flow, rather than dividing the flow in half and irrigating at the same time. First, Moncada would use the whole flow for a week; during which not all of its lands would be serviced (see below); then the other WUAs would take over, 
alternating just as they had done before, but now using twice the previous amount of water. The result was a stable two-week cycle covering the majority of the irrigated lands in the Huerta.

The crucial thing to understand about this massive voluntary reduction in the intensity of people's water use - one that is apparently unprecedented in the world literature on irrigation - is that it was accomplished in such a way that, over a large part of the system, all of the operating principles were preserved. This discovery again confirmed our hypothesis, showing that it is the principles underlying the working rules - which themselves are somewhat changeable - that make the Valencia system so robust. However, an additional drought measure was also implemented at the time over roughly half the total area, one that compromised the principles of uniformity and contiguity and greatly complicated the task of monitoring.

A prioritization among crops was introduced by putting one of them - oranges on a much lower frequency, effectively creating a separate cycle for irrigating citrus crops. Note that this rule only took effect in Moncada, which covers slightly more than half of the total land in the Huerta. It is the only WUA where a significant amount of citrus is produced (on approximately $74 \%$ of its land). During the drought, citrus trees were only entitled to be watered every 45 days, which meant that farmers could only irrigate them, along with the other crops, during every fourth turn of the general twoweek cycle. This limit was implemented in Moncada without putting the matter to a vote, apparently being accepted by the farmers for several reasons.

First of all, some further curtailment was necessary in order to achieve the required 50\% reduction, and this change affected the farmers in the WUA fairly equally because most of them do produce some citrus crops. Secondly, orange trees are able to withstand aridity much better than the other crops grown locally; even in the best of times they do not need watering more than once every three weeks or 21 days. Hence the restriction was seen as causing a minimal amount of harm, one that fell rather evenly on most of the farming households. Fourthly, most of the farmers had access to wells upon which they could rely to take up the slack, as we will see below. Finally, the restriction was a traditional one, even though it had not had to be implemented for many years.

When asked about how the restriction was enforced, from a practical point of view, both farmers and water officials explained that monitoring had to be intensified throughout the system, with some also acknowledging that most of this burden now fell 
heavily on the water distributors and less so on the farmers themselves. By all accounts this was a big challenge, but one that the Guardas in Moncada rose to successfully.

The widespread use of the groundwater was crucial in adapting to the drought, but in order to appreciate its role an important point must be understood. Up until passage of the Water Law of 1985, groundwater was legally regarded as a separate resource, essentially an open-access one suitable for private exploitation (Guillet, 2000, 1997). Although the WUAs could have drilled wells for communal use prior to that time, adding the groundwater to the river water and then using the two flows together, only one of the groups, Tormos, assumed the management of a well previously drilled by a group of farmers. Thus the groundwater historically had little to do with the tradition of communal irrigation in the Huerta.

However, in 2006 the JDWA, as part of its drought adaptation plan, drilled one large emergency well for communal use in each of the canal WUAs (MAGRAMA, 2007). That groundwater is now combined with the river water, and both are used conjunctively - with the JDWA's permission - throughout the canal system of each usergroup whenever the conditions require it. Thus its communal distribution and use are, in the case of those particular wells, governed by the same principles as the river water.

The number of 'private' well societies in the Huerta today clearly runs in the hundreds, but our efforts to specify it were unfortunately not successful. At least 75 were confirmed to exist within the nine WUAs of the inner Huerta (Ortega-Reig, 2009), which in each case can be considered overlapping surface and groundwater water user associations. However, two of those user-groups - Mislata and Rovella — do not have any wells, for reasons that are not entirely clear. Several hundred more were reportedly established through time in Moncada, some of which are no longer operating today (Ortega-Reig, 2011).

The JDWA is now in the process of trying to register all of the active ones, a process that is also underway in other parts of Spain. Local water officials appear somewhat reluctant to divulge much information about them, mainly because they fear that a full disclosure will cause their traditional rights to the river water to be reduced. That traditional entitlement, to surface flows that also provide the city with its drinking water supply, is increasingly being challenged today in the local media of the Valencia region, as the amount of river water continues to dwindle.

The groundwater is extracted from the wells at a steady rate by coin-operated 
electric pumps, and fed into the canal networks spanning specific command areas within the Huerta. Although some are used "on demand" much of the time, these largely 'private' wells are only operated when the canals lie empty, i.e. when the river water is not circulating. Irrigators must buy the special-purpose coins, called fichas, from well-society officers, but they do so at two different rates. Founding members of the societies - i.e. people who contributed to the initial well costs - pay a discounted hourly rate, while non-members pay substantially more when making a water purchase, up to twice that amount. However, all landowners within a given well's command area have the right of access; and no one who wants the water and is willing to pay for it can be denied. In this sense, use of the wells conforms to the principle that the frequency of irrigation must be the same for everyone using a given source of water.

Two other arrangements affect the amount of groundwater that can be used each time a person irrigates from a well. In some societies, membership and water access are based only on the possession of land (or in some cases of land-shares) in the well's command area, so that under normal conditions irrigation is on-demand and water purchases are not limited in any way. During droughts, however, such use is restricted by making the frequency of irrigation the same for all fields, and by limiting watering time per hectare to a single ratio or proportional amount. In this sense, the use of the groundwater - again, a fairly recent development — has been strongly shaped by the Huerta's long tradition of communal water use.

In other societies, access to the well water is based on the initial buying, by farmers, of individual time-shares, which did not necessarily have to be proportional to the land area irrigated, although one suspects that they probably were in most cases. Here, however, water purchases are limited to a uniform number of hours per share, under both normal and drought conditions. During droughts, however, a further restriction is imposed, namely alternation or turn-taking: a farmer cannot buy or use more coins to start the next round until everyone who wishes to irrigate in a given cycle has taken their turn (Ortega-Reig, 2009, p. 39). The watering frequency under emergency conditions is thus the same for everyone, again revealing a strong shaping effect.

It is important to point out that, despite the fairly liberal and uniform rules of access to the wells, significant portions of the total areas served by some of the Huerta WUAs remain excluded, being out of reach of any of the 'private' water: e.g., approximately $60 \%$ of Quart, $52 \%$ of Mestalla, and from 3\% to $10 \%$ of Xirivella, Rascanya, and 
Favarra. Moreover, two of the canal WUAs have no private wells at all, continuing to rely almost entirely on the use of the river water and an additional emergency well. This disadvantage becomes doubly great once one takes into account the fact that the other canal WUAs - those that have wells - have the option of purchasing well water in bulk from the well societies, for communal or collective use when they need it. Several WUAs did this repeatedly during the recent drought, spending a lot of money — funds pooled together by the farmers - in order to deal with the three-year emergency.

The interviews showed that the well water is routinely used during years of normal rainfall in order to prevent delays in situations where the precise timing of irrigation is critical, such as during crop planting. The more regular use during droughts is far more important, but this is done specifically in order to supplement, or effectively to shorten, the general cycle of surface-water use. The farmers strongly prefer the water of the Turia River, due to its very low cost and relatively good quality. Thus the more expensive - and slightly saline - groundwater was used during the drought to irrigate a second time, in the week immediately following the twice-monthly cycle of surfacewater use (which itself took one week), in order to limit the total time that passed between waterings to one week rather than two, specifically to benefit commercial crops (excepting oranges) (Andreu et al., 2010).

Most farmers did this, despite the substantial increase in their production costs, in order to maintain the high quality standards that are imposed today by the supermarkets, both domestic and foreign, especially in the production of melons, onions, and garden vegetables. In Moncada, many of the orange producers also relied heavily on purchased water during the drought. They used the groundwater, again as a supplement but in a less regular manner, in order to make certain that no more than 20 to 30 days passed between irrigations, a limit that otherwise could not have been maintained.

The significance of this advantage should again be emphasized, as should the resulting inequity, not among people's water rights but in their actual access to the resource. Many of the excluded farmers feel that both kinds of water should be communally owned, and that the two flows should be combined and used together for the benefit of everyone, as is the case with the emergency wells. Such criticism was either expressed directly or implied in the remarks of most of the farmers who felt that the Valencia tradition, while equitable and highly successful in comparison to most others, 
is still far from perfect.

One of the most important things we were able to confirm was that, despite the much higher frequency of groundwater purchases during droughts, the rate of water theft remained amazingly low, even though it was higher than during the years of 'normal' rainfall. Glick (1970, pp. 54-59) and Ostrom (1990, pp. 74-75) were the first scholars of Valencia to explore this matter, using remarkable records of the 15th-century from nearby Castellón - a highly similar but much smaller Huerta - to argue that the rate of theft in Valencia during medieval times was probably similarly low. The two authors were able to calculate that the Castellón farmers were fined for rule violations at a rate of only $.008 \%$ per year, with an average of 200 fines issued each year during a period when the farmers together irrigated more than 25,000 times annually, which of course were opportunities to steal water. This rate, however, did amount to more than one fine per day, indicating that a high level of vigilance prevailed at that time throughout the system.

This argument based on extrapolation through both space and time was bolstered recently by Favrettto (2004), who was able to gain access to the written records of Valencia's Water Tribunal and to count the number of denuncias, or formal accusations of rule violations, that were sustained and punished by the court each year during the period from 1945 to 2002 . Her analysis documents a notable decline throughout the entire period in the rate of infractions of all kinds, but particularly in those for water theft. Interestingly, beginning in the 1980's there was a conspicuous drop in reports of infractions that she categorizes as 'traditional' - e.g., those attributable to people's efforts to get more water, or to their tendency to waste it or take it out-of-turn - and a marked increase in violations associated with, or attributable to, the ongoing process of urbanization, such as building in the canal right-of-way, or throwing contaminated water and refuse into the canals.

Favretto's data can be used to calculate the extremely low rate of accusations of water theft that prevailed in the inner Huerta during the latter half of the 20th century. Throughout the 57-year period, the thousands of farmers there would have had more than 90,000 opportunities to steal water each year, during at least 24 turns of a two-week watering cycle (or 48 turns of a one-week cycle). Yet the number of fines issued each year for theft varied from only 1 to as many as 49, with a mean of 15.6 and a large standard deviation of 16.0. The rate of reported theft during the entire period 
was therefore $.0002 \%$ per year, which amounted to an average of only 2 cases reported during every million acts of irrigation. This translates into less than one reported theft for every round of the irrigation cycle for the inner Huerta, which involved more than 10,000 farmers.

The pattern was equally impressive during this time in the other half of the irrigation system, in Moncada. We were able to gain access to the records of its Water Tribunal for the 12-year period from 1999 to 2011, which included both normal and drought years (Ortega-Reig, 2011, p. 75). During the years of normal rainfall (2001, 2002, 2003, 2004, 2009, and 2010), the rate of reported theft was .000003\% per year, with only 8 complaints adjudicated during the entire 6-year period. During the years considered ones of drought, including the recent emergency (1999, 2000, 2005, 2006, $2007,2008)$, the rate was nearly four times as high, or $.00001 \%$ per year. Yet this amounted to only 16 cases reported during that entire time, among more than 9800 irrigating farmers. As Ostrom (1990, p. 74) basically predicted in her analysis, the rate is generally astonishingly low, but it remains sensitive to the prevailing conditions; it could be doubled, tripled, or even quadrupled and yet still indicate a remarkable degree of conformance with the rules. To call Valencia's tradition successful and robust is therefore to understate greatly the hydrological and social reality. The degree of social order and cooperation sustained in Valencia throughout the years and even the centuries, in situations of prevailing scarcity, may well be unrivalled anywhere else on the planet.

\subsection{Discussion: the hypothesis of convergent evolution}

The striking parallels among the institutions existing today in Valencia and those in the previously-studied systems in Peru are evidently the result of convergent social evolution: the emergence, among unrelated and distinct societies, of highly similar adaptations to similar environmental conditions, in these cases to general aridity and to drought. It is extremely unlikely that traditional practices in Valencia somehow diffused to the communities in the Andes where the operating principles were first identified. All of those communities are small indigenous villages, located in high-mountain valleys noted for their geographic remoteness (Trawick, 2001a, 2001b; Treacy, 1994a, 1994b).

The possibility does have to be considered, since farmers from Spain's Mediterranean coast are known to have migrated to other parts of the New World quite early in the colonial period. Spanish colonists, probably originating from the area 
around the city of Granada, established themselves at that time in northern Mexico and in what would eventually become New Mexico in the U.S., bringing with them practices and techniques of Islamic origin and building entirely new irrigation systems, ones apparently modelled on Valencia's. In some of these acequia systems a highly similar "canal culture" persists to this day (Brown and Rivera, 2000; Cox and Ross, 2011; Rivera, 1998).

There is no evidence that this happened in Peru, however. There, the villages and irrigation systems - including those previously studied (Trawick, 2003a, 2003b, 1994; Treacy, 1994a, 1994b) — are known to have predated the arrival of the Spanish by hundreds of years, having been built by the Incas and their predecessors. Independent emergence is a far more plausible explanation, a phenomenon that probably occurred for one simple reason: the principles of operation are simple and yet work extremely well. Indeed, when found together as a set, we feel that they form a kind of optimal social configuration, a model for coping effectively with scarcity and with drought, at least for a certain type of farmer.

The possibility of a direct evolutionary link arising from the colonial system of governance has been discussed elsewhere, and there is no need to review that argument fully here (Trawick, 2001a). In her analysis of Valencia, Ostrom (1990, p. 81) observes that the policies and practices imposed by the Spanish Crown in governing the New World generally originated in Castile, in central and western Spain, at a time when the municipalities of the Mediterranean coast - those belonging to the eastern kingdom of Aragón, such as Valencia - were largely autonomous, especially in irrigation, a freedom they had been enjoying for centuries. She notes that colonial governance policies were generally "modelled on Castile" rather than Aragon, and the evidence on early water law in Peru strongly bears this out.

In ethnohistorical research done on Cuzco, the former Inca capital, during the 17th-century, Villanueva and Sherbondy (1979, p. xvii) have shown that the colonial Spaniards, who partly reorganized local irrigation in Peru at that time, imposed foreign practices only on the lands that they directly owned and controlled — the haciendas while they "...respected the ancient water regime of the lands of the indigenas and left the distribution of water in their hands, according to ancient usage". That policy was still faithfully followed more than two centuries later in the provisions of Peru's Water Law of 1902 (Pasapera, 1902), which was closely modelled on the earlier Spanish Water 
Law (Trawick, 2003a, pp. 159-160). Both laws stipulated that water utilization in the indigenous communities was to continue undisrupted, and to follow traditional 'uses and customs'. The colonial policy was a dual one based on the feudal pattern of allowing private ownership of water on hacienda lands - thus mirroring traditional practices in Castile rather than Aragon — while not interfering with indigenous practices in any way ${ }^{12}$.

In considering the convergence hypothesis, it is important to note that the specific rules from which the operating principles are derived, although similar today in the various systems in question, are not identical. For example, the order of water distribution and use in the Peruvian communities, while fixed and contiguous, appears to be bottom-up in every case rather than top-down as in Valencia. Such a reversal is hardly the kind of change one would expect to be imposed by the rulers of a rigid and feudal colonial society, especially if those people came from Valencia.

Furthermore, the terminology of local practices in the two cases - although exhibiting the kind of overlap one would expect to see today in Peru, when nearly all people in the highlands are bilingual and fluent in Spanish - is linguistically distinct. In the Peruvian communities, the local terms denoting key elements of the distinctive kind of irrigation system being described here - from diversion dams (yutas), tanks (qochas) and canals (yarqhas) to turn-taking (mitay), equitable water shares (rakis), and standard water-containment features (atus) — are in Quechua, the Inca language (Trawick, 2003a, 2003b, 2001a, 2001b; Treacy, 1994a, 1994b). Today those terms coexist with, but probably pre-date, their Spanish counterparts, which admittedly are also used. But one does not see this kind of dual terminology in parts of North America that were colonized by people originating from the Valencia region. There the only terms used are Spanish (Rivera, 1998, pp. 227-232), obviously because the local irrigation traditions were established by Spanish people rather than by indigenous ones, as in Peru.

Finally, and most importantly, there is the fact that highly similar communitymanaged irrigation systems - ones likely to conform to the same model — clearly exist in many other parts of the world. There too farmers appear to have converged on the same set of principles in learning to cope with scarcity. The various comparative analyses of successful systems that have been done to date all cite proportionality among rights

12. See Trawick's discussion (2001a, p. 363) of Garcilazo's well-known ethnohistorial account of how irrigation was supposedly carried out in the provinces under the Incas, one that mentions most of the principles discussed here and is entirely consistent with the moral economy model. 
and duties (Coward, 1979; Maass and Anderson, 1978; Ostrom and Gardner, 1993; Siy, 1982; Wade, 1986), or among benefits and costs (Agrawal, 2002; Baland and Platteau, 1996; Ostrom, 2005, 1992, 1990; Tang, 1992) as the central organizing principle. In so doing, they point to an important commonality in the way that the central value of equity, or fairness, is defined in a great many local irrigation societies throughout the world. It can be said to arise from the fact that in nearly all of them water is seen as directly, and inseparably, tied to the land.

If it is true, however, that water rights cannot be proportional to each other unless the irrigation frequency is the same for everyone - as the farmers in both Valencia and in the Peruvian systems seem to insist - and unless watering techniques are also fairly uniform, then such uniformity is highly likely to exist in most or all of those previouslystudied systems. As was the case in Valencia, the principle may have been overlooked, or perhaps been implicitly assumed to exist, in the earlier published accounts. In either event, its full significance was clearly not understood.

If such uniformity is indeed present, then most of the successful systems documented to date in the world literature must conform to a single model. Based on that likelihood, we assert that this type of equitable, transparent, and robust irrigation system - which we call the "moral economy of water" (Trawick, 2010, 2008, 2001a, 2001b) - has emerged repeatedly, and often independently, in many different parts of the globe, wherever small farmers have learned to cooperate in coping successfully with a persistent scarcity. It appears to exist in hundreds of locally-governed canal systems, of various scales and degrees of social complexity, in Peru (Treacy, 1994a, 1994b), Spain, Mexico (Palerm-Viqueira and Martínez-Saldaña, 2000), New Mexico (Cox and Ross, 2011; Rivera, 1998), India (Wade, 1987, 1986), Nepal (Lam, 1998; Ostrom and Gardner, 1993; Shivakoti and Ostrom, 2002), Bali (Lansing, 1987, 2006, 1991), and the Philippines (Coward, 1979; Siy, 1982), as well as in many Islamic countries.

The principles do work extremely well, which must explain why they have repeatedly been invented or discovered and then adopted so widely in coping with scarcity. This ethnological point can now be appreciated from both the emic, or culturespecific perspective of the local farmers, and also from a more etic, or scientific and pan-cultural, point of view. When found together as a set that underlies local practices, the principles interact in a unique way, forming a kind of integrated whole or model, a configuration whose combined effect is to strongly reinforce people's motivation to obey 
the agreed-upon rules.

Note that this incentive is basically a positive one, rather than a merely negative one resting on the near certainty that any violators of the rules will be detected and punished. And here the uniform frequency of irrigation, that most basic commonality and equality among people's water rights, is the key, as the vast majority of our interviews in both Spain and Peru have confirmed.

The arrangement is of course fair, and for that reason uniformity should perhaps be seen as inherent in, or as logically implied by, the principle of proportionality. But it is crucial for practical reasons as well as moral ones. Such uniformity has the effect of creating a direct and obvious link, to the individual farmer, between the 'efficiency' and orderliness of water use and the duration of the irrigation cycle, one that cannot be created through any other kind of institutional arrangement.

When everyone waters their land in a single rotation, and when any expansion of the overall system is prohibited, the water saved by people through frugality and selfrestraint causes the distribution cycle - the great circle turning at the heart of things - to run faster. This is in part because it minimizes the total surface area of canals in use at each moment in time, this reducing evaporation and filtration. By limiting watering to the shortest acceptable period and by obeying the rules, people are thus able - quite visibly and obviously - to irrigate more often, as often as possible throughout the year and from a long-term point of view. This benefit was captured beautifully in one Valencia farmer's account of irrigation during the dry season of a normal year:

"...we endeavor to be there at the edge of the field waiting for the water when it arrives, standing as next in line, so that we finish quickly and in that way the water arrives at Puçol and then returns. [With] this 'water wheel' that we make, we are irrigating every eight days, and we don't spend money on the wells." (Ortega-Reig, 2011, p. 67).

This image of a noria or water wheel is a striking metaphor for the kind of maximizing and yet self-restrained and cooperative behavior that clearly predominates throughout the Valencia system. People standardize and limit their own water consumption in the short term in order to maximize its availability for themselves and everyone else in the long term. Such behavior is mostly inwardly focused within each local user group, in response to what is widely perceived to be a basic compatibility, even a congruity, between individual self-interest and the common good, two social constructs that are often defined in purely abstract terms and assumed to be opposed. 
In an irrigation system of this kind, the peculiar characteristics of water make it possible, not just to mediate, but to transcend this most basic of all conceptual oppositions. Most of the people interviewed in Valencia, like many of those involved in the earlier studies in Peru, seem to see the two concepts as entirely compatible in irrigation, provided that the watering frequency is the same for everyone. In this regard, the farmer's reference to eight days in the above quote is extremely significant, and drives home the point being made.

Today the river water circulates in Valencia during the seasonal low water of a 'normal' year for one week, while during a drought year the duration is two weeks; this refers to how long the main canal gates remain open in each WUA. But there is an additional delay of one day that passes between irrigations for each person in each of those cycles, due to the fact that the water, once released, is somewhat slower to circulate and to be used throughout the canal system. In our interviews, farmers invariably referred to people irrigating every 8 days or every 15 days, and, unless they were Sindics or Guardas, they never described cycles as lasting one week or two, nor did we ever hear reference to 7 days or 14 days passing between waterings, a discrepancy that was puzzling to us at first.

The reason has since become clear: the length of the formal distribution cycles and the number of days that pass between waterings are two different things. In explaining how the system works, farmers invariably focus on the latter — unlike the water officials - because that number is far more important from a social point of view, being the most basic thing that the farmers have in common. The discrepancy, it should be noted, cannot be inferred logically from the written ordenanzas; its existence can only be discovered through interviews and then ultimately confirmed through observation.

In an irrigation system of this kind, free-riders - people who ignore the rules and sometimes succumb to the temptation to steal water or to waste it - interfere with the efforts of others to shorten the watering cycle and instead cause it to lengthen and slow down. The arrangement generates strong social pressures against such behavior, pressures that, in a highly transparent system, are ultimately effective in controlling a category of persons who are highly stigmatized in Valencia, just as they are in Peru: “espavilats" [exceedingly bold or brazen individuals] "parásitos" [parasites]; "ratas" [rats], “listos” [literally 'sharp ones'], and “personajes “ [characters or 'important' persons] are terms that were consistently used in referring to such individuals. And, as more than one 
farmer in Moncada observed,“...they are always the same characters, and all of us know who they are." (Ortega-Reig, 2011, p. 68).

The central adaptive feature - a strong incentive to be both efficient and vigilant so as to maximize the frequency of irrigation for one's self and for everyone else - is clearly evident in the use of surface water in Valencia, as we have seen. It makes possible the integrated use of the two kinds of water in successfully adapting to drought, a process that, on the basis of the river water alone, has been going on in the Huerta for centuries. The set of institutions which creates that basic and successful adaptation can now be fully appreciated, one that must also exist in a great many other systems throughout the world, 'peasant' or smallholder systems in every case.

Note that the entire Valencia tradition rests on this equitable and robust foundation. The customary and regular use of the river water makes possible the parallel but more periodic and limited use of groundwater, specifically in order to meet the high crop-quality standards that competing in the global 'marketplace' nowadays imposes, a competitive social pressure that comes into the foreground most forcefully during droughts. This pattern of syncopated and supplementary groundwater use, built on a foundation of equitable but adjustable surface-water use, parallels a similar arrangement found in some of the previously studied communities in the Andes (Trawick, 2003a, $2003 \mathrm{~b}, 1994)$. Thus it is not entirely unique to Valencia. The arrangement is, however - despite its current inequities - notably more 'efficient' and sustainable than the practices prevailing today in most other parts of the world.

Before concluding, it is important to point out that, with the one notable exception of the Water Tribunal, the hydraulic tradition in Valencia is predominantly secular and lacks any element of ritual. The contrast could hardly be greater with the previously studied systems in Peru, where farmers clean the main canals together each year through communal and highly festive group labor, after making burnt offerings and drinking to the mountain deities (Gelles, 2000; Trawick, 2003a, 2003b, 1994; Treacy, 1994a, 1994b).

In Valencia there are no priests and water temples, such those of the famous subaks of Bali (Lansing, 1987, 2006, 1991), just a weekly public court that is a rather sombre affair, witnessed silently by hundreds of onlookers. Yet even in the case of Bali the similarities with the Water Court are obvious; and important matters are, in both cases, ultimately decided democratically by the farmers, with or without the blessing 
and the guidance of the goddesses and gods.

It is possible that a stronger ritual dimension once existed but has gradually been lost in Valencia, which, like other cities in Spain, is widely known for its vibrant annual saint's day fiesta. In any case, the largely secular nature of the local tradition shows that big group celebrations, as exciting and expressive of comunitas as they are, are not necessary in order to maintain order in irrigation and to renew a strong ethos of cooperation. A number of factors appear to interact in Valencia to sustain that communal spirit, all of them necessary but probably not sufficient conditions that encourage success, both here and in other parts of the world: a high degree of cultural homogeneity, a limited range of stratification among households, and small farms with similar but not identical water needs.

Ultimately, however, the authority of the elected leaders and the hired water guards, like the quasi-sacred character of the rules themselves - both written and unwritten - are vested in the fact that they are outcomes of collective choice and collective action. Above all, they are effective and they work, maintaining an equity and transparency almost as reliable as the circular motion of a noria, a water wheel.

\subsection{Conclusion}

In concluding, it is worth considering some of the reasons why the widespread existence of this kind of successful local irrigation society has not previously been recognized. The argument for convergent evolution has been made before, though only briefly, in discussions of the Peruvian data (Trawick, 2001a, 2001b) and in preliminary overviews of the research that was then ongoing in Spain (Trawick, 2010, 2008). Those presentations relied mainly on reading between the lines of the existing literature, arguing that uniformity had to exist wherever proportionality did, in Valencia and more widely throughout the world. That initial argument drew little response, but the ensuing silence and apparent scepticism of readers seemed to rest on two critical foundations.

One set of readers, exemplified by Boelens and his research group (Boelens and Dávila, 1998; Boelens and Hoogendam, 2002; Roth et al., 2005), has consistently taken the position that equity in irrigation means different things to different people, that fairness is defined and achieved in very diverse ways in various settings throughout the world. There is said to be no significant commonality among those local definitions, and little to be learned from looking at them comparatively and ethnologically, as we 
have done here.

This research group, which has done remarkable work on irrigation development in many locales in Latin America, has thankfully been one of the most prominent defenders of the water rights of indigenous people and peasant farmers, in the Andes and elsewhere. Those rights are under threat today, by mining companies, chemical companies, and agribusinesses (Bebbington, 2009), all driven by the same relentless processes of expanding consumption and rapid urban growth that threaten the rights of the farmers in Valencia.

Their defence, however, has been couched in a language (Boelens, 2008) expressing opposition to all forms of conceptual abstraction, hostility to analytical models, even an antipathy towards generalization itself. The clear implication is that such abstract thinking is always aimed at the "normalization" or standardization of local practice, and is therefore ethnocentric, neo-colonialist and hegemonic, peculiar to the dominant Western tradition and the capitalist way of life, and certainly alien to the thought of indigenous people. This is simply not true, as our research in both Peru and in Spain has shown. We feel that the interests of indigenous people and peasant farmers have not been adequately served by adherence to this post-modernist and post-structuralist position, however fashionable it may have been during the last three decades.

To defend "difference" as somehow inherently valuable, no matter what forms it takes, is clearly problematic, in irrigation or in any other domain of social life, especially when underlying similarities or commonalities in practice are ignored. And the position has certainly been counterproductive in an era when competition over tightening water supplies is demanding, quite inevitably, that peoples' use of the resource be shown empirically to be 'efficient'.

A second set of readers, exemplified by Mosse (2006a, 2006b, 2003), has, in a similar way, expressed great scepticism that any set of rules or principles exists which can lead, in a predictable way, to desired social outcomes. The many variables of social history and physical setting are said to be so complex and specific in irrigation that they will ultimately defeat people's intentional efforts to adapt to them. It is therefore questionable that such a thing as a successful or robust irrigation system even exists; and we can certainly never predict what the outcome of a particular local effort to create one will be. 
Importantly, it is Mosse who has shown, based on an analysis of several cases in India, that the rules supposedly governing communal irrigation systems often turn out to be idealized representations bearing little resemblance to social reality. Indeed, his firm scepticism has been one of the main forces driving us forward in this research, in an effort to provide the kind of documentation - grounded in interviews if not always in comprehensive ethnography - that would allow a rebuttal. And we believe that we have finally done that here.

As Mosse demonstrates quite clearly, the Indian systems he analyzes so closely - which appear to conform to the moral economy model in theory but not in practice were never 'bottom-up' or self-organized and self-governing systems, either in their construction or in their operation, until the very recent devolution of governance responsibility to local farmers under a program of national irrigation reform. Thus it is hardly surprising that, in local village societies based on ancient and rigid divisions of caste, the outcome today is widely as he describes, featuring marked discrepancies in the frequency with which people actually get their water. The cases do demonstrate that no set of rules - even the simple and elegant set that we have defined here - is selfenforcing, but surely that is something we already knew.

If the "moral economy of water" does exist in all of these parts of the world, in so many different local settings, then clearly it is of great theoretical and practical significance. The evidence would now appear to be abundant, and convincing, that this kind of irrigation system can be built intentionally around an explicit set of rules, in a way that does produce somewhat predictable outcomes. The resulting systems are often equitable, transparent, and robust, as well as being both socially and environmentally sustainable. And they are based on a distinctive, and eminently social, idea: that irrigation is about sharing a scarcity of water fairly among fields and households, not about providing optimal amounts of water to crops.

The underlying principles strongly promote efficiency in water use, as we have seen, in order to minimize the prevailing scarcity. But that benefit remains firmly tied to the land, so that it can be enjoyed by all fields, all landowners, and all crops, equitably and in proportional amounts, as Maass and Anderson first recognized. The uniformity principle is, however, the key to why the system often works so well. And it, in turn, is based on an assumption of scarcity, the idea that in irrigation - as in so many other domains of social life - there is often far less than enough to go around. Under this kind 
of regime, decisions about the crops are left up to the farmers and their families, and the system is in no way designed with crop requirements in mind.

That being the case, the moral economy type of system departs fundamentally from, and even opposes, the agronomic and technocratic model that guided government water policy throughout most of the world during the 20th century, a model that also underlies recent neo-liberal proposals for worldwide water reform (World Bank, 2004). Therein lies its real contribution: the challenge that it poses, based on the traditional practices of indigenous people and peasants all over the world, to business-as-usual in irrigation, and even to nearly all forms of national water law (e.g., Peru's 1969 law, or the current law of Ecuador, as well as Peru's 2009 reform law).

The conventional model, which provides the foundation of most of those laws and remains hegemonic today in most countries, is based on the idea that irrigation is about meeting the water 'needs' of crops, providing plants with optimal amounts through procedures too complex for local people themselves, without technical assistance, to oversee. It in turn rests on the assumption that enough water is available to do this, an idea that, in many parts of the world, has outlived any usefulness it may once have had as a basic approach. Because of it, irrigation under scarcity has long been seen as a special case or an intermittent challenge, rather than as being the normal state-of-affairs.

Provided that surface water is used sparingly and equitably during its yearly fluctuations, in the manner we have described here, there may be, under some circumstances - perhaps even in a great many local cases - enough groundwater available to supplement routine irrigation and to meet the 'needs' of the most important crops. In such situations it may be possible to optimize water allocation for commercial crop production, as in Valencia, by using groundwater regularly as a supplement and then employing it especially intensively during droughts. But the agronomic model is ultimately neither adaptive nor sustainable as a basic approach, one standing on its own, in a context of growing scarcity being induced by population growth and climate change. We feel that the management of water resources in many parts of the world will not prove to be successful in the long run unless it is rebuilt on a moral economy foundation.

Some authors (Bakker, 2011, 2007; Bolding et al., 1995; Mollinga et al., 2007), in pointing to the limitations of community-based irrigation - and of participatory approaches to resource management more generally - have cited the literature on farmer- 
managed systems, specifically those where (as in India) operation and maintenance have recently been taken out of the hands of government bureaucracies and turned over to local irrigator groups. This "Big Bang" devolution of management responsibility was carried out, primarily in large-scale canal systems of surface-water use, in many countries beginning in the 1970's: e.g. in India (Bharadwaj, 1990; Narain, 2003; Sengupta, 1991), the Philippines (Korten, 1982; Siy, 1989), Mexico (OECD, 2013), and even in Peru (Trawick, 2003b). And the results proved to be mixed, exhibiting in many cases failures in which the uncontrolled local use of groundwater is now a serious problem.

Several authors, most significantly Ostrom (2007), have rightly noted that this massive experiment showed that community-based management is not a panacea, any more than water markets are, or state bureaucratic control, an assertion with which we heartily agree. They argue that we should therefore abandon the search for simple solutions based on primary reliance on a single approach to management.

Yet, throughout all of these national attempts at reform through devolution, the agronomic model for irrigation has remained dominant, guiding most local efforts to change the way things were done. The idea that different crops require different amounts of water - and that they should get it, on different schedules and cycles - has reigned supreme as the basic approach (Bharadwaj, 1990; Narain, 2003, pp. 26-30; Sengupta, 1991). Unfortunately, in the hands of small farmers and peasants, who often grow the same array of crops and whose water needs are therefore fairly uniform, it is a recipe for chaos and conflict, at least when water is scarce. Systems based on this approach are invariably opaque, rather than transparent ${ }^{13}$; and people lack any strong incentive to conserve the resource because they irrigate at several different frequencies on different cycles in an order that is, above all, flexible and changeable. The crucial link that can provide farmers with an incentive to be 'efficient', the link between the conditions of individual water use and the duration of the watering cycle, does not exist. Unfortunately, the farmers in the large-scale government-built systems that have recently been reformed, apparently lacking any management tradition of their own peasant farmers in nearly all cases - were given no other model to guide them ${ }^{14}$.

13. See Trawick (2003a), Chapter 7 for a well-documented example in Peru.

14. The famous warabandi systems of Pakistan and India, the largest in the world, were of course strongly promoted by the World Bank for more than a decade as both a model and a test case for decentralization and for participatory irrigation management (Khan, 1984, pp. 26-30; Malhotra, 1982; Singh, 1984). The problem with this plan, and the main reason for its disappointing 
How different might the results have been, had these reforms been guided by a different model, a more traditional one based on more realistic assumptions? Perhaps someday we will have the opportunity to find out. The evidence now available suggests that the jury may still be out on these massive efforts to bring about much-needed change. But it is no longer out on the merits, or at least the potentials, of communitymanaged irrigation, on the capacity of small farmers to successfully manage their own water, in a world characterized increasingly by fluctuation and scarcity.

results, is that in the warabandis there is no link, in the eyes of the farmers, between the 'efficiency' of their water use and the duration of the irrigation cycle. The frequency and duration of people's turns are both fixed but the amount of water available to them each time is not, so that under scarcity farmers are unable to irrigate all of their fields and often all of their crops in each turn. One turn is thus not necessarily equivalent to another, and more than one is often necessary to irrigate all of a person's land. Thus, by using water more frugally, farmers are not therefore able to irrigate more often, a form of negative feedback and maximization of benefit that is crucial to the success of the moral economy type of system. The warabandis are so enormous, consisting of 50,000-hectare blocks of land, that this crucial link does not and apparently cannot exist. Furthermore, they were not initially bottom-up organizations, either in their construction or their operation, having been built in the late 19th and early 20th centuries by the colonial British. 